Original Article

\title{
Effect of computerized cognitive rehabilitation program on cognitive function and activities of living in stroke patients
}

\author{
Chanuk Yoo ${ }^{1)}$, Mi-hyun Yong ${ }^{2)}$, Jaeyeop ChunG ${ }^{3)}$, Yeongae YanG ${ }^{4}{ }^{*}$ \\ 1) Department of Occupational Therapy, Hanlyo University, Republic of Korea \\ 2) Department of Occupational Therapy, College of Health, Kyungwoon University, Republic of Korea \\ 3) Department of Occupational Therapy, Kyongbuk Science College, Republic of Korea \\ 4) Department of Occupational Therapy, College of Biomedical Sciences and Engineering, Inje \\ University: Gimhae, Republic of Korea
}

\begin{abstract}
Purpose] The objective of this study was to examine the effect of cognitive rehabilitation using a computer on cognitive function and activities of daily living in stroke patients presenting impairment of cognitive function. [Subjects] Forty-six stroke patients were divided into two groups (a training group and control group) through random assignment. [Methods] The training group received rehabilitation therapy and an additional computerized cognitive rehabilitation program using The RehaCom software 30 minutes/day, 5 times/week for 5 weeks. The control group received only rehabilitation therapy including physical and occupational therapy. A comparative analysis on all subjects was conducted before and after the experiment using a cognitive test and activities of daily living test. [Results] After 5 weeks of therapy, the training group presented statistically significant improvement in cognitive function assessment items of digit span, visual span, visual learning, auditory continuous performance, visual continuous performance, and others compared with the control group but did not present statistically significant improvement in activities of daily living. [Conclusion] It was revealed through this study that computerized cognitive rehabilitation with the RehaCom program results in improvement in cognitive function and can be used as a treatment tool beneficial to stroke patients presenting cognitive impairment.

Key words: Computerized cognitive rehabilitation, Cognitive function, Activities of daily living
\end{abstract}

(This article was submitted Apr. 2, 2015, and was accepted Apr. 24, 2015)

\section{INTRODUCTION}

Cognitive function refers to the ability to understand events that occur in our daily living and ability to make decisions and adapt in a variety of environments ${ }^{1)}$. Impairment in cognitive function is a common symptom in stroke patients, and it brings about difficulties in concentration, memory, and problem solving ability. It not only acts as the biggest impairment for daily living but also acts as the impairment for rehabilitation in local society ${ }^{2,3)}$.

In the case of conducting cognitive rehabilitation using a computer, it is easier to induce motivation for therapy because direct feedback can be given to patients regarding the performance result in comparison with cognitive rehabilitation, and this type of training can not only provide flexibility but may also shorten treatment time $\mathrm{e}^{4,5}$. A previous study suggested that cognitive rehabilitation using a computer has

*Corresponding author. Yeongae Yang (E-mail: otyya62@ inje.ac.kr)

C2015 The Society of Physical Therapy Science. Published by IPEC Inc. This is an open-access article distributed under the terms of the Creative Commons Attribution Non-Commercial No Derivatives (by-ncnd) License $<$ http://creativecommons.org/licenses/by-nc-nd/3.0/>. an effect on cognitive function in patients with brain damage, and other previous studies suggested that continuous computerized cognitive rehabilitation for 5 months or longer improves the cognitive ability of elderly individuals with low cognitive ability ${ }^{6,7)}$. Therefore, numerous studies have been conducted on computerized cognitive rehabilitation. In particular, many studies have been conducted with themes concerning attention and memory, and such studies and interests have been concentrated on basic cognition level. However, given that there has been a increase in attention paid to improvement of cognitive function and activities of daily living, there has been a lack of study on the degree of improvement in cognitive function resulting from computerized cognitive rehabilitation and its effect on daily living.

Therefore, the objective of this study was to verify the effect of computerized cognitive rehabilitation by comparing the level of cognitive improvement between a general rehabilitation therapy group and computerized cognitive rehabilitation group and examining the effect of improved cognitive level on activities of daily living.

\section{SUBJECTS AND METHODS}

The experiment in this study was conducted with 46 stroke patients who were receiving in-patient rehabilitation 
therapy at Inje University Hospital from Oct. 2013 to Mar. 2014. The participants understood the objective of this study and provided written informed consent prior to participation in the study. The study was approved by the ethics committee of the Inje University Institutional Review Board for Clinical Studies. The participants were randomly divided into a training group of 23 patients and a control group of 23 patients. The training group received rehabilitation therapy and an additional computerized cognitive rehabilitation program using the RehaCom software 30 minutes/day, 5 times/week for 5 weeks. The control group received only rehabilitation therapy, including physical and occupational therapy.

The Computerized Neuropsychological Test (CNT) was used for assessment of cognitive function, and the Functional Independence Measurement (FIM) was used for assessment of activities of daily living.

In regard to the CNT, 7 tests, the digit span test, verbal learning test, visual span test, visual learning test, auditory continuous performance test, visual continuous performance test, and trail making test, were used in the assessment to measure the degree of cognitive function ${ }^{8)}$. The FIM is composed of 13 items regarding 4 lower domains of physical function, self-care, sphincter control, transfers, and locomotion, and 5 items regarding 2 lower domains of cognitive function, communication and social cognition. The responses are recorded on a 7-point Likert scale, and 1-5 points and 6-7 points are considered to indicate a dependent state in which assistance is required and an independent state in which assistance is not required, respectively. The total number of points is calculated by adding the points together for each question, with the total ranging from 18 to 126 points; a higher total number of points signifies a greater capacity to perform activities of daily living independently $\left.{ }^{9}, 10\right)$. The inter-rater reliability of the FIM has been found to be between 0.83 and 0.99 , and the test-retest reliability has been found to be between 0.48 and $0.93^{11)}$. Cognitive assessment and activities of daily living assessment were conducted before and 5 weeks after the start of computerized cognitive rehabilitation.

The RehaCom software (Hasomed GmbH, Magdeburg, Germany) was used for computerized cognitive rehabilitation; the treatment sessions lasted $30 \mathrm{~min}$ and were held 5 times/week for total of 5 weeks. The cognitive training program employed was composed of attention, focus, memory, spatial imagination, visual impairment, and visuomotor coordination. Computerized cognitive rehabilitation together with rehabilitation therapy was conducted for the training group, and rehabilitation therapy only was conducted for the control group.

The paired t-test was conducted for comparison of differences between the computerized cognitive rehabilitation group and control group in each test, and the level of statistical significance was set as $\alpha=0.05$. The PASW Statistics for Window software (Version 18.0, SPSS Inc., Chicago, IL, USA) was used for statistical processing of data.

\section{RESULTS}

There were 8 male and 15 female study participants in the training group, and their average age and post-onset duration were 53.2 years and 11.8 months, respectively. There were
Table 1. Clinical characteristic of the study participants $(n=46)$

\begin{tabular}{lcc}
\hline & $\begin{array}{c}\text { Training group } \\
(\mathrm{n}=23)\end{array}$ & $\begin{array}{c}\text { Control group } \\
(\mathrm{n}=23)\end{array}$ \\
\hline Gender (Male: Female) & $8: 15$ & $9: 14$ \\
Age (years) & $53.2 \pm 8.8$ & $56.3 \pm 7.9$ \\
Post-onset duration (months) & $11.8 \pm 7.5$ & $10.7 \pm 6.2$ \\
\hline
\end{tabular}

Mean \pm SD

9 male and 14 female participants in the control group, and their average age and post-onset duration were 56.3 years and 10.7 months, respectively (Table 1).

Comparison of the results from before and after therapy revealed that training group presented statistically significant improvement in digit span, visual span, visual learning, auditory continuous performance, and visual continuous performance $(\mathrm{p}<0.05)$ (Table 2). However, computerized cognitive rehabilitation did not result in statistically significant difference between before and after therapy in verbal learning, trail making, and functional independence measure $(\mathrm{p}>0.05)$ (Table 2).

Comparison of the results from before and after therapy revealed that the control group did not present statistically significant difference in any of the assessment items including digit span, verbal learning, visual span, visual learning, auditory continuous performance, visual continuous performance, trail making, functional independence measure $(\mathrm{p}>0.05)$ (Table 2).

\section{DISCUSSION}

In this study, the effect of therapy using a computerized cognitive rehabilitation system (called RehaCom) was examined. The RehaCom computerized cognitive rehabilitation system used in this study is composed of 20 detailed training programs for effective rehabilitation of cognitive function impairment. These programs are designed to work together and are composed of not only special and basic items but also a variety of items that closely mimic reality. In comparison with cognitive rehabilitation the strengths of rehabilitation with RehaCom are that it enables adjustment of difficulty based on the task performance capacity of the patient, immediate feedback, reduction in time spent by the therapist once the patient learns the therapy task, and maintenance of objective and continuous information concerning performance results ${ }^{8}$. The objective of RehaCom is effective and economic therapy for patients, and all RehaCom therapy programs enable this objective, as they are based on academically verified theory.

The present study was conducted based on the results of preceding studies; although there was no statistically significant difference in cognitive ability between the training group and control group in each test item before therapy, there was improvement in cognitive assessment after therapy. Thus, the present study revealed that computerized cognitive rehabilitation has effect on improvement of cognitive function in stroke patients $(\mathrm{p}<0.05)$. In particular, it resulted in improvement in digit span, visual span, visual learning, 
Table 2. Comparison of variables between before and after therapy in each group

\begin{tabular}{lccc}
\hline Variable & & Training group & Control group \\
\hline Digit span test & Before & $3.62 \pm 1.35$ & $3.72 \pm 1.23$ \\
(score) & After & $4.32 \pm 1.32^{*}$ & $3.86 \pm 1.41$ \\
Verbal learning test & Before & $3.55 \pm 2.12$ & $3.54 \pm 2.08$ \\
(score) & After & $3.65 \pm 2.35$ & $3.58 \pm 2.26$ \\
Visual span test & Before & $3.61 \pm 1.08$ & $3.62 \pm 1.20$ \\
(score) & After & $4.56 \pm 1.52^{*}$ & $3.67 \pm 1.52$ \\
Visual learning test & Before & $4.21 \pm 1.46$ & $4.31 \pm 1.43$ \\
(score) & After & $4.66 \pm 1.84^{* *}$ & $4.43 \pm 1.66$ \\
Auditory continuous performance test & Before & $0.55 \pm 0.22$ & $0.52 \pm 0.12$ \\
(sec) & After & $0.45 \pm 0.34^{*}$ & $0.49 \pm 0.52$ \\
Visual continuous performance test & Before & $0.56 \pm 0.24$ & $0.54 \pm 0.18$ \\
(sec) & After & $0.46 \pm 0.33^{*}$ & $0.50 \pm 0.68$ \\
Trail making test & Before & $71.62 \pm 22.31$ & $68.48 \pm 25.54$ \\
(sec) & After & $65.68 \pm 24.51$ & $67.36 \pm 22.50$ \\
Functional Independence Measure & Before & $73.34 \pm 20.51$ & $75.56 \pm 19.65$ \\
(score) & After & $84.25 \pm 22.50$ & $80.36 \pm 18.25$ \\
\hline
\end{tabular}

Mean \pm SD.

*Significant difference $\mathrm{p}<0.05$. $* *$ Significant difference $\mathrm{p}<0.01$

auditory continuous performance, and visual continuous performance. Furthermore, its results are similar to those of Chen et al. and Lee et al. ${ }^{12,13)}$, who suggested that computerized cognitive rehabilitation is effective for recovery of cognitive function of patients presenting cognitive impairment after brain damage when conducted together with rehabilitation therapy. However, although the training group presented a high increase in average points compared with the control group in the activities of daily living scale, no statistically significant difference was found before and after the experiment. Since other physical aspects are incorporated with cognitive aspects for the activities of daily living scale, it would have been difficult for a short-term cognitive treatment of ( 5 weeks) to result in a significant difference in activities of daily living.

A limitation of this study was implementation of computerized cognitive rehabilitation with adjustment of difficulty based on the performance of each subject rather than according to the traits of the subjects. Moreover, it was difficult to examine whether or not the improvement in the cognitive domain of activities of daily living was due to pure improvement in cognitive function because the physical domain was included together with cognitive domain in the total points for the activities of daily living assessment.

The results of the present study revealed that computerized cognitive rehabilitation is effective for recovery of cognitive function in stroke patients who present cognitive impairment. In future studies, it is necessary to conduct studies with subjects classified by post-onset duration of stroke, damaged area, and cognitive function.

\section{REFERENCES}

1) McAllister TW: Cognitive functioning in the affective disorders. Compr Psychiatry, 1981, 22: 572-586. [Medline] [CrossRef]

2) Dam M, Tonin $P$, Casson $S$, et al.: The effects of long-term rehabilitation therapy on poststroke hemiplegic patients. Stroke, 1993, 24: 1186-1191. [Medline] [CrossRef]

3) Patel MD, Coshall C, Rudd AG, et al.: Cognitive impairment after stroke: clinical determinants and its associations with long-term stroke outcomes. J Am Geriatr Soc, 2002, 50: 700-706. [Medline] [CrossRef]

4) Palmese CA, Raskin SA: The rehabilitation of attention in individuals with mild traumatic brain injury, using the APT-II programme. Brain Inj, 2000, 14: 535-548. [Medline] [CrossRef]

5) Lee YM, Jang C, Bak IH, et al.: Effects of computer-assisted cognitive rehabilitation training on the cognition and static balance of the elderly. J Phys Ther Sci, 2013, 25: 1475-1477. [Medline] [CrossRef]

6) Gontkovsky ST, McDonald NB, Clark PG, et al.: Current directions in computer-assisted cognitive rehabilitation. NeuroRehabilitation, 2002, 17: 195-199. [Medline]

7) Günther VK, Schäfer P, Holzner BJ, et al.: Long-term improvements in cognitive performance through computer-assisted cognitive training: a pilot study in a residential home for older people. Aging Ment Health, 2003, 7: 200-206. [Medline] [CrossRef]

8) Glisky EL, Schacter DL, Tulving E: Computer learning by memory-impaired patients: acquisition and retention of complex knowledge. Neuropsychologia, 1986, 24: 313-328. [Medline] [CrossRef]

9) Keith RA, Granger CV, Hamilton BB, et al.: The functional independence measure: a new tool for rehabilitation. Adv Clin Rehabil, 1987, 1: 6-18. [Medline]

10) Trombly CA, Radomski MV, Trexel C, et al.: Occupational therapy and achievement of self-identified goals by adults with acquired brain injury: phase II. Am J Occup Ther, 2002, 56: 489-498. [Medline] [CrossRef]

11) Dickson HG, Köhler F: Interrater reliability of the 7-level functional independence measure (FIM). Scand J Rehabil Med, 1995, 27: 253-256. [Medline]

12) Chen SH, Thomas JD, Glueckauf RL, et al.: The effectiveness of computer-assisted cognitive rehabilitation for persons with traumatic brain injury. Brain Inj, 1997, 11: 197-209. [Medline] [CrossRef]

13) Lee IH, Park SY, Son CS, et al.: Clinical trial evaluating an online cognitive dysfunction evaluation system for stroke patients. J Phys Ther Sci, 2012, 24: 503-507. [CrossRef] 